\title{
Bilateral Massive Pulmonary Embolism on Disseminated Intravascular Coagulation (DIVC) after Severe Postpartum Haemorrhage
}

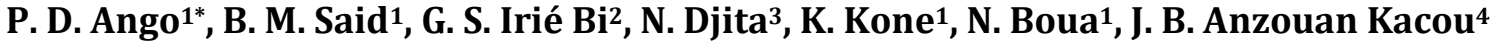 \\ ${ }^{1}$ Department of Resuscitation and Anesthesia, University Hospital Center of Treichville (CHUT), Abidjan, Côte d'Ivoire \\ ${ }^{2}$ Department of Resuscitation and Anesthesia, University Hospital Center of Bouaké (CHUB), Bouaké, Côte d'Ivoire \\ ${ }^{3}$ Department of Cardiology, Hospital Center of Alençon, Alençon, France \\ ${ }^{4}$ Abidjan Heart Institute (ICA) Head of Department of Medical Cardiology, Abidjan, Côte d'Ivoire \\ Email: *privatango@yahoo.fr
}

How to cite this paper: Ango, P.D., Said, B.M., Irié Bi, G.S., Djita, N., Kone, K., Boua, N. and Anzouan Kacou, J.B. (2018) Bilateral Massive Pulmonary Embolism on Disseminated Intravascular Coagulation (DIVC) after Severe Postpartum Haemorrhage. Open Journal of Anesthesiology, 8, 85-92. https://doi.org/10.4236/ojanes.2018.83009

Received: February 14, 2018

Accepted: March 18, 2018

Published: March 21, 2018

Copyright $\odot 2018$ by authors and Scientific Research Publishing Inc. This work is licensed under the Creative Commons Attribution International License (CC BY 4.0).

http://creativecommons.org/licenses/by/4.0/

\begin{abstract}
The authors report a case of bilateral pulmonary embolism (PE) with intermediate risk at the University Hospital center of Treichville (CHUT). This is a postpartum $\mathrm{PE}$ in a 37-year-old obese, multiparous woman with postpartum hemorrhage from uterine rupture after vaginal delivery initiated by injectable oxytocin. This postpartum haemorrhage was managed by massive transfusion and hysterectomy. The initiation of thromboprophylaxis was delayed in view of its coagulation record, the first 3 days. Later, the patient presented respiratory distress for which the completion of a pulmonary angioscanner made it possible to make the diagnosis of $\mathrm{PE}$ whose clinical evolution under heparinotherapy was favorable.
\end{abstract}

\section{Keywords}

Pulmonary Embolism, Postpartum Hemorrhage, Disseminated Intravascular Coagulation, Thromboprophylaxis

\section{Introduction}

Pulmonary embolism (PE) is part of venous thromboembolism (VTE). It is a very common pathology whose current epidemiological data are estimated at more than 100,000 with annual incidence of 10 to 20,000 deaths per year in France [1] [2] [3]. In pregnant women, the risk of occurrence of PE is high. Physiological changes in haemostasis expose the pregnant woman to the risk of thromboembolic events [4] [5] [6] [7] [8]. In the case we report, this risk is increased by performing an obstetric surgery. The occurrence of postpartum 
hemorrhage complication associated with significant thrombocytopenia and a collapsed prothrombin level did not allow the practitioner to introduce effective postoperative thromboembolic prevention as early as possible.

\section{Case Report}

Mrs A.T. born on May 14, 1980, was admitted to the gynecology-obstetrics department of Treichville on September 6, 2017 for metrorrhagia on a pregnancy of 41 Weeks of Amenorrhea. In this department, an ultrasound found a grade III placenta normally inserted without image of detachment. It was decided to initiate a vaginal delivery with oxytocin. The delivery took place on the same day without epidural with expulsion of a female newborn weighing $3510 \mathrm{~g}$ with an Apgar score of 9 at one minute and 10 at five minutes. She received 10 IU oxytocin at the time of delivery with a tonic uterus, but bleeding persisted with postpartum haemorrhage having required uterine revision under general anesthesia. After this revision, an uterine rupture was diagnosed with hemorrhagic shock (blood pressure: 93/45 $\mathrm{mmHg}$ ), and disseminated intravascular coagulation (DIVC). The preoperative assessment revealed a hemoglobin $(\mathrm{Hg})$ rate of $6.8 \mathrm{~g} / \mathrm{dl}(12$ - 16.4), platelets with 74,000 elements (170 $\left.375 \times 10^{3}\right)$, a TCA $>120(26-40.4)$, a prothrombin rate at $15 \%(70 \%-100 \%)$ and a fibrinogen $0.6 \mathrm{~g} / \mathrm{l}(1.9-4.3)$. The patient underwent a transfusion of globular concentrate (17 bags) iso-rhesus iso-group and plasma (15 bags) before admission to the operating room. She was admitted to the operating room at $\mathrm{H} 7$ for hemostasis surgery where a total hysterectomy was performed. In immediate post operatory, the hemoglobin level was $13.5 \mathrm{~g} / \mathrm{dl}$ and platelets were 38,000 elements. She did not receive preventive anticoagulation in view of her coagulation record. After discussion with the gynecologists, the anticoagulation started on third day (September 9, 2017) in the evening with first walk on the folowing day (September 10, 2017). The evolution during hospitalization in the obstetric gynecology department was marked by the appearance on fourth day (September 10, 2017) postoperative dyspnea in deep inspiration, with left basal thoracic pain and oxygen desaturation at $87 \%$. The hemodynamic state was stable, the calves were soft and pulmonary auscultation was normal. The patient is put on oxygen therapy glasses at $3 \mathrm{l} / \mathrm{min}$ to obtain a $\mathrm{SaO}_{2}$ at $98 \%$. A cardiological opinion was requested as well as additional examinations, and the patient was transferred to the intensive care unit of the University Hospital Center of Treichville.

\section{History}

We note an asthma, an osteosynthesis for a fracture of the tibia and fibula and an appendicectomy operated for more than 5 years, in this Obese patient (BMI at $32.2 \mathrm{~kg} / \mathrm{m}^{2}$ ).

G9 P8 with 6 vaginal deliveries and a caesarean delivery, the 4th for fetal heart rate abnormality. She is also allergic to amoxicillin-clavulanic acid. We did not 
note any personal or family pulmonary embolism.

\section{Physical Examination}

The cardiological physical examination shows a haemodynamic stability with blood pressure (BP) at $130 / 80 \mathrm{mmHg}$, a eupneic patient at rest, without chest pain with free lungs. The sounds of the heart were regular without breathing, absence of left and right ventricular failure. The abdomen is supple and depressible, painless, marked by a high parietal adiposity impeding deep palpation. The neurological examination notes the absence of sensitivomotor deficit. In addition, the bandage of the surgical wound was clean.

\section{Paraclinical Examination}

Chest CT angiography performed on September 10 revealed a massive bilateral pulmonary embolism, involving the right and left proximal pulmonary arteries, with left-sided pleurisy (Figure 1). We note, moreover, a thrombus on a right proximal branch (box 1), and no impact on the pulmonary parenchyma (Figure 2). The ECG showed steady sinus rhythm at $75 \mathrm{bpm}$, normal repolarization, and absence of atrioventricular and intraventricular conduction disorder.

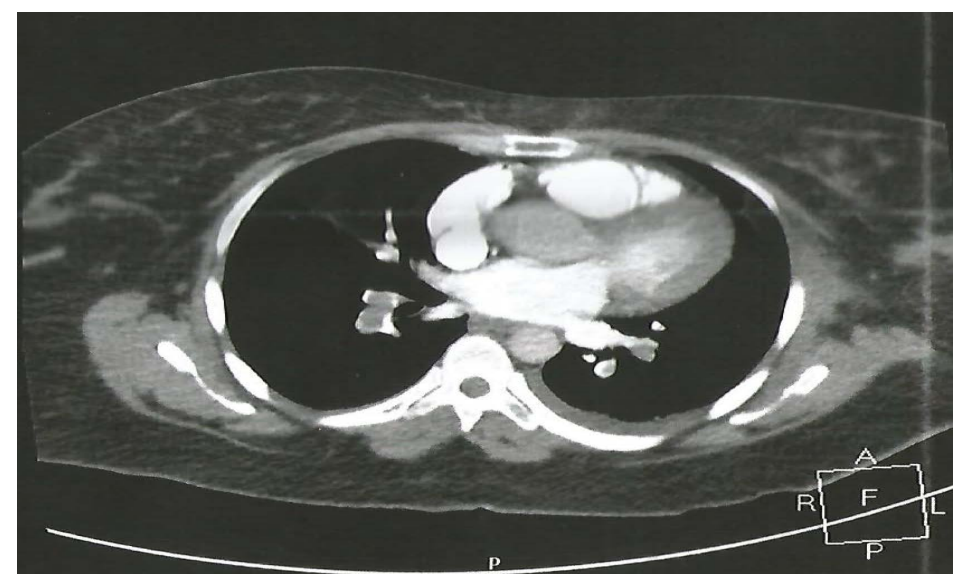

Figure 1. Pulmonary embolism of the left and right proximal trunks with a small amount of left reaction pleurisy, right distal branch thrombus.

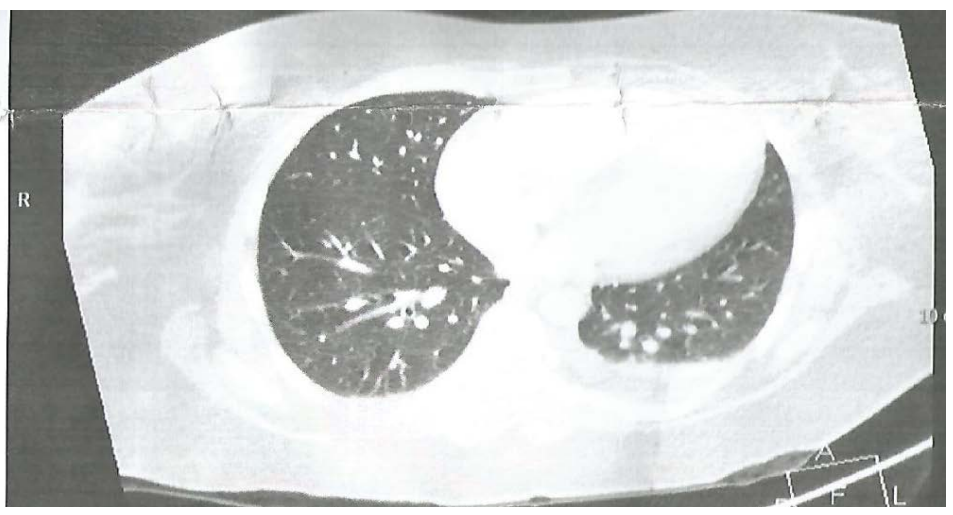

Figure 2. No pulmonary reaction on this Radiography. 
Transthoracic Ultrasound showed a non dilated Left Ventricle (LV) with a 56\% LV Ejection Fraction (LVEF), a paradoxical Interventricular Septum. The right ventricle was normokinetic TAPSE (Tricuspid Annulat Plane Systolic Excursion) at $21 \mathrm{~mm}$, systolic pulmonary arterial pressure (SPAP) at $34+15$ $\mathrm{mm}$ HG; an Inferior Vein Cave (IVC) dilated not very compliant. The pericardium was normal.

Biology: C-reactive protein (CRP) was $9 \mathrm{mg} / \mathrm{l}$. Thrombocytopenia at 33,000 improved to 70,000 and then to $138,000 / \mathrm{mm}^{3}$. The renal status was normal. BNP (Brain Natriuretic Peptide) was high. Troponin was positive at $0.21 \mathrm{ng} / \mathrm{ml}$.

The venous doppler of the lower limbs (VDLL) did not find deep vein thrombosis.

\section{Treatment}

The patient underwent anticoagulation with unfractionated heparin $300 \mathrm{mg} /$ day in Electrical Injection Venous Intra (IVSE) with a target TCA of 2.5 in combination with previscan, analgesia with Nefopam, oral paracetamol, prevention of stress ulcer with Esomeprazole $20 \mathrm{mg}$, antibiotic therapy with ciprofloxacin.

\section{Evolution}

Favorable under treatment, clinically marked by the absence of chest pain, and by hemodynamic stability. From the biological point of view, the Blood Formula count had revealed platelets with 212,000 elements per $\mathrm{mm}^{3}$, an HB level of 12 $\mathrm{g} / \mathrm{dl}$ and a hypokalemia of 3.4.

\section{Discussion}

This clinical case illustrates the following difficulties in an African context: the prevention and management of thromboembolic disease in a patient with thromboembolic risk factors associated with a risk of bleeding; management of unfractionated heparin in DIVC with severe thrombocytopenia; intermittent availability of blood products; the diffusion of medical information between the different specialties; the absence of a hematologist in the management of this patient.

This bleeding facilitated the uncontrolled systemic activation of the hemostatic system to simultaneous generalized microvascular thrombosis [7] leading to heart failure in our patient. The venous thrombotic risk major is based on risk factors realeted to the patient that are either transient (prolonged immobilization of more than 3 days, fractures of the lower limbs in the last 3 months, travel, hormones) or permanent [9] [10]. Our patient had three permanent risk factors: obesity, age (age $>35$ years) and multiple pregnancies [11] [12] [13] [14]. Obesity has been recognized for decades as a major risk factor of cardiovascular and venous thromboembolic diseases [12]. As for pregnancy, the physiological changes (in particular those of hemostasis) make 
the pregnant woman a patient with a high thrombotic risk. From the third trimester of pregnancy, fibrinogen, factors VII, VIII, X, XII and von Willebrand increase [15]. Prothrombin II increases from early pregnancy to an average of $130 \%$ between 10th and 19th Weeks of Amenorrhea and then tends to return to normal. At the same time, there is an increase in the level of tissue plasminogen activator inhibitors [16] [17]. There could be at least two inhibitors of plasminogen activators (PAI 1 and PAI 2) in the maternal serum, one of which is derived from endothelial cells and the other from the placenta [18]. All inhibitors of plasmin formation increase during pregnancy with a consequent decrease in fibrinolytic activity during pregnancy [18].

There is also a decrease in venous flow from the 25th week of amenorrhea to 6 weeks postpartum and a decrease in protein $S$ [15].

Uterine rupture, severe postpartum haemorrhage, massive transfusion of blood concentrate, associated with other risk factors present during pregnancy, have been the cause of hypercoagulability, hypo-fibrinolysis [2]. Initially, these modifications allow the maternal organism to prepare for delivery and to prevent the risk of uterine bleeding associated with delivery. On the other hand, they increase the risk of thromboembolic accidents and many studies suggest the existence of a certain degree of intravascular coagulation as early as the fifteenth week of pregnancy due to the increase of procoagulant factors and the reduction of thrombolytic activity [16] [19]. Acute obstetric bleeding in our patient has been associated with rapid consumption of coagulation factors and considered to be one of the main causes of disseminated intravascular coagulation (DIC) [20] [21]. Postpartum thromboprophylaxis should take into account the level of risk, especially when the order ratio (OR) becomes greater than 3 (age > 35, obesity, multiparity, urgent cesarean section and severe hemorrhage of post partum) [22]. In our study, in view of the abundant haemorrhage requiring a surgical procedure $(\mathrm{OR}=12)$ [22] associated with a highly disturbed balance of coagulation, the prevention of postoperative thromboembolic disease could only be initiated to day four (September 10, 2017), which was contrary to formalized expert recommendations [4] [5] [8] [23]. It is the realization of a thoracic angioscanner as Gold standard practice, before any thoracic pain associated or not with dyspnea appearing in a context of obstetric surgery, [8] [10] [23] which allowed to make very early the diagnosis of pulmonary embolism. However, the absence of the D Dimer assay is noticeable because of the high clinical probability but also because physiologically we observe in pregnant women a very significant increase in these D Dimers [24]. Their utility to rule out a venous thromboembolic disease (VTE) is very limited until 4th week postpartum [25]. The initial severity of pulmonary embolism is assessed by the simplified Pulmonary Embolism Severity Index (sPESI), allowing the risk of death to be assessed within 30 days [10] [22]. It seems best validated to select patients at risk of early mortality [26] [27] [28]. This stratification score of early mortality risk makes it possible to classify our patient in the category of 
intermediate risk pulmonary embolism (stable hemodynamics, elevation of biological markers) with a score greater than or equal to 1 and therefore a mortality rate equal to $11 \%$. The mangement is based on this assessment. The strategy adopted to manage a pulmonary embolism without shock with unfractionated heparin gave very good clinical results and the patient was discharged from her hospitalization of the intensive care unit on the third day.

\section{Conclusion}

This observation confirms the appearance of pulmonary embolism after an abundant haemorrhage requiring postpartum surgery. It highlights the importance of prevention of thromboembolic disease in the postpartum period and the implication of the physiological changes of pregnancy in the occurrence of this complication. Like all recent studies, it demonstrates the value of thoracic CT angiography for the diagnosis of pulmonary embolism, thus enabling an early management and improving the prognosis.

\section{Conflicts of Interest}

The authors have no conflicts of interest to declare.

\section{References}

[1] Wells, P.S., Forgie, M.A. and Rodger, M.A. (2014) Treatment of Venous Thromboembolism. JAMA, 311, 717-728. https://doi.org/10.1001/jama.2014.65

[2] Bilger, A., Pottecher, J., Greget, M., Boudier, E. and Diemunsch, P. (2014) Extensive Pulmonary Embolism after Severe Postpartum Haemorrhage: Management with an Inferior Vena Cava Filter. International Journal of Obstetric Anesthesia, 23, 390-393. https://doi.org/10.1016/j.ijoa.2014.06.002

[3] Martillotti, G., Boehlen, F., Robert-Ebadi, H., Jastrow, N., Righini, M. and Blondon, M. (2017) Treatment Options for Severe Pulmonary Embolism during Pregnancy and the Postpartum Period: A Systematic Review. Journal of Thrombosis and Haemostasis, 15, 1942-1950. https://doi.org/10.1111/jth.13802

[4] Bates, S.M., Greer, I.A., Middeldorp, S., Veenstra, D.L., Prabulos, A.M., et al. (2012) VTE, Thrombophilia, Antithrombotic Therapy, and Pregnancy: Antithrombotic Therapy and Prevention of Thrombosis. American College of Chest Physicians Evidence-Based Clinical Practice Guidelines. Chest, 141, e691S-e736S.

[5] Samama, C.M., Albaladejo, P., Laversin, S. and Marret, E. (2005) Prevention of Venous Thromboembolism in Surgery and Obstetrics. Annales Françaises d Anesthésie et de Réanimation, 24, 853-861. https://doi.org/10.1016/j.annfar.2005.06.011

[6] Tsikouras, P., von Tempelhoff, G.F. and Rath, W. (2017) Epidemiologie, Risikofaktoren und Risikostratifizierung venöser Thromboembolien in Schwangerschaft und Wochenbett. Zeitschrift fur Geburtshilfe und Neonatologie, 221, 161-174.

[7] Gjonbrataj1, E., Kim, J.N., Gjonbrataj, J., Jung, H.I., Kim, H.J. and Choi, W.-I. (2017) Risk Factors Associated with Provoked Pulmonary Embolism. The Korean Journal of Internal Medicine, 32, 95-101.

[8] Royal College of Obstetricians, Gynaecologists (RCOG). (2015) Reducing the Risk of Venous Thromboembolism during Pregnancy and the Puerperium (Green-Top 
Guideline No. 37a).

https://www.rcog.org.uk/en/guidelines-research-services/guidelines/gtg37a/

[9] Mismetti, P., Baud, J.M., Becker, F., Belmahdi, F., Blanchard, P., Constans, J., et al. (2010) Guidelines for Good Clinical Practice: Prevention and Treatment of Venous Thromboembolism in Medical Patients. Journal des Maladies Vasculaires, 35, 127-136. https://doi.org/10.1016/j.jmv.2009.12.002

[10] Galanaud, J.-P., et al. (2015) Management of pulmonary embolism: A 2015 Update. Journal des Maladies Vasculaires, 41, 51-62. https://doi.org/10.1016/j.jmv.2015.07.003

[11] Bakebe, A., Kashongwe, I., Mulenga, C., Tshiasuma, M., et al. (2017) Pulmonary Embolism: Epidemiological Data and Diagnosis in Kinshasa Hospitals. International Union against Tuberculosis and Lung Disease, 21, 875-879. https://doi.org/10.5588/ijtld.16.0418

[12] Pessinaba, S., Atti, Y.D.M., Baragou, S., Pio, M., et al. (2017) L'embolie pulmonaire au centre hospitalier universitaire Campus de Lomé (Togo): étude rétrospective à propos de 51 cas. Pan African Medical Journal, 27, 129. https://doi.org/10.11604/pamj.2017.27.129.6855

[13] Knight, M. (2008) Antenatal Pulmonary Embolism: Risk Factors, Management and Outcomes. British Journal of Obstetrics and Gynaecology, 115, 453-461. https://doi.org/10.1111/j.1471-0528.2007.01622.x

[14] Lindqvist, P., Dahlbäck, B. and Maršál, K. (1999) Thrombotic Risk during Pregnancy: A Population Study. Obstetrics \& Gynecology, 94, 595-599. https://doi.org/10.1097/00006250-199910000-00021

[15] Macklon, N.S. and Greer, I.A. (1997) The Deep Venous System in the Puerperium: An Ultrasound Study. British Journal of Obstetrics and Gynaecology, 104, 198-200. https://doi.org/10.1111/j.1471-0528.1997.tb11044.x

[16] Gerbasi, F.R., Bottoms, S., Farag, A. and Mammen, E.F. (1990) Changes in Hemostasis Activity during Delivery and the Immediate Postpartum Period. American Journal of Obstetrics \& Gynecology, 162, 1158-1163. https://doi.org/10.1016/0002-9378(90)90006-S

[17] Gore, M., Eldon, S., Trofatter, K.F., Soong, S.J. and Pizzo, S.V. (1987) Pregnancy-Induced Changes in the Fibrinolytic Balance: Evidence for Defective Release of Tissue Plasminogen Activator and Increased Levels of the Fast-Acting Tissue Plasminogen Activator Inhibitor. American Journal of Obstetrics \& Gynecology, 156, 674-680. https://doi.org/10.1016/0002-9378(87)90076-7

[18] Kruithof, E.K., Tran-Thang, C., Gudinchet, A., Hauert, J., Nicoloso, G., Genton, C., Welti, H. and Bachmann, F. (1987) Fibrinolysis in Pregnancy: A Study of Plasminogen Activator Inhibitors. Blood, 69, 460-466.

[19] Nicolas, P. (2015) Prophylaxie de la maladie veineuse thromboembolique en post-partum: étude de pratique au CHU de Brest en 2013-2014. Médecine humaine et pathologie.

[20] Rattray, D.D., O'Connell, C.M. and Baskett, T.F. (2012) Acute Disseminated Intravascular Coagulation in Obstetrics: A Tertiary Centre Population Review (1980 to 2009). Journal of Obstetrics and Gynaecology Canada, 34, 341-347. https://doi.org/10.1016/S1701-2163(16)35214-8

[21] Santos, S.M., Cunha, S., Baptista, R., Monteiro, S., Monteiro, P., Gonçalves, F. and Pêgo, M. (2017) Early, Real-World Experience with Direct Oral Anticoagulants in the Treatment of Intermediate-High Risk Acute Pulmonary Embolism. Revista Portuguesa de Cardiologia, 36, 801-806. https://doi.org/10.1016/j.repc.2017.01.010 
[22] Fuchs, F. and Benhamou, D. (2015) Césarienne et post-partum. Recommandations pour la pratique clinique. Journal de Gynécologie Obstétrique et Biologie de la Reproduction, 44, 1111-1117. https://doi.org/10.1016/j.jgyn.2015.09.020

[23] Chan, W.S., Rey, E., Kent, N.E., Group VTEiPGW, Chan, W.S., et al. (2014) Venous Thromboembolism and Antithrombotic Therapy in Pregnancy. Journal of Obstetrics and Gynaecology Canada, 36, 527-553. https://doi.org/10.1016/S1701-2163(15)30569-7

[24] Ballegeer, V., Mombaerts, P., Declerck, P.J., Spitz, B., Van Assche, F.A. and Collen, D. (1987) Fibrinolytic Response to Venous Occlusion and Fibrin Fragment D-Dimer Levels in Normal and Complicated Pregnancy. Thrombosis and Haemostasis, 58, 1030-1032.

[25] Boehlen, F., Epiney, M., Boulvain, M., Irion, O. and de Moerloose, P. (2005) Evolution des D-Dimères durant la grossesse et le post partum: résultats de deux études. Revue Médicale Suisse, 1, 296-298.

[26] Zhou, X.Y., Ben, S.Q., Chen, H.L. and Ni, S.S. (2012) The Prognostic Value of Pulmonary Embolism Severity Index in Acute Pulmonary Embolism: A Meta-Analysis. Respiratory Research, 13, 111. https://doi.org/10.1186/1465-9921-13-111

[27] Thachil, J. and Toh, C.H. (2009) Disseminated Intravascular Coagulation in Obstetric Disorders and Its Acute Haematological Management. Blood Reviews, 23, 167-176. https://doi.org/10.1016/j.blre.2009.04.002

[28] Levi, M. and Ten Cate, H. (1999) Disseminated Intravascular Coagulation. The New England Journal of Medicine, 341, 586-592.

https://doi.org/10.1056/NEJM199908193410807 